\title{
The Strategic Landscape of Industry 4.0
}

\author{
Børge Sjøbakk \\ SINTEF Technology and Society, P.O. Box 4760 Torgarden, 7465 Trondheim, Norway \\ borge.sjobakkesintef.no
}

\begin{abstract}
We are currently on the marks of Industry 4.0. Characterized by increased digitalization and automation, it is expected to overturn traditional business models and supply chains. Industry 4.0 initiatives have already made significant impact on industry, and will continue to do so in the years to come. While the concept of Industry 4.0 gains a foothold, there is no clear idea of how it should be addressed by companies. The transformation is without a doubt a strategic imperative that requires long-term commitment. Instead of investing in new technologies in an ad hoc manner, companies need to adopt a systematic approach to address technological opportunities throughout the supply chain. There exist many different and, in some cases, conflicting opinions about the scope of such an approach, what it should contain, its point of departure, etc. This paper synthesizes such views into a framework that depicts the strategic landscape manufacturing companies are facing at the outset of their digital journey. The framework can be used to position and discuss companies' digitalization and automation initiatives with respect to business-, manufacturing-, supply chain-, and digital strategy.
\end{abstract}

Keywords: Industry 4.0, Factory of the Future, Digital Supply Networks.

\section{Introduction}

We are currently on the marks of Industry 4.0. Characterized by increased digitalization and automation, it is expected to overturn traditional business models and supply chains. Industry 4.0 initiatives have already made significant impact on industry, and will continue to do so in the years to come. The topic is virtually on every manufacturing company's agenda, as many (rightly) feel they are left with no choice but to go with the flow to remain competitive. History has shown that organizations that ignore the need for change are rapidly forced out of the market [1]. Currently, early adopters are implementing new technologies at a fast pace, and build capabilities that enable them to increase their lead [2]. Although the full shift toward Industry 4.0 may not be realized in decades, some argue that key advances will be established and winners and losers will emerge in the next five to ten years [3]. Therefore, to remain competitive, companies will need to accelerate their efforts towards Industry 4.0 [2].

While the concept of Industry 4.0 gains a foothold, there is no clear idea of how it should actually be addressed by companies [1]. In the past 10 to 15 years many companies have made large technology investments which have helped to standardize and 
improve the efficiency of fragmented processes [4]. Implementation of digital initiatives in silos or through a technology centric approach are persisting trends [5]. Even though these companies might realize short-term benefits from ad-hoc implementation of state-of-the-art digital technologies, they are likely to miss out on greater opportunities [1] - such as transparency and seamless planning and execution throughout the extended supply chain [4].

Although there is no common understanding of how organizations should adapt to Industry 4.0, such a transformation is without a doubt a strategic imperative that requires long-term commitment [1]. Instead of investing in new technologies in an ad hoc manner, companies need to adopt a systematic approach to address technological opportunities throughout the supply chain [6,7]. There exist many different and, in some cases, conflicting opinions about the scope of such an approach, what it should contain, its point of departure, etc. The purpose of this paper is to synthesize such views into a framework that depicts the strategic landscape manufacturing companies are facing at the outset of their digital journey. Companies can use the framework to position and discuss their digitalization and automation initiatives with respect to business-, manufacturing-, supply chain-, and digital strategy.

The remainder of the paper is structured as follows. First, the research method is described. This is followed by a brief overview of Industry 4.0, including an understanding of the term and the technology trends constituting it, as well as two underlying transformations of Industry 4.0 - from traditional factories and supply chains to Factories of the Future and Digital Supply Networks, respectively. Thereafter, the multifaceted strategic landscape is presented. Finally, the results are discussed and concluded.

\section{Research Method}

The strategic landscape of Industry 4.0 is proposed based on a study of publicly available reports from leading global management consulting companies. The reports were identified through Google searches for <company name $>+\langle$ keywords $\rangle$ in the fall 2017. The keywords used were 'Industry 4.0', 'digital supply chain' and 'digital factory'. A total of 32 reports were studied for definitions and recommendations, especially emphasizing strategic issues related to the transformation towards Industry 4.0. Different views have been synthesized into the framework presented in this paper.

Business reports as a genre have a set of unique features, including funnel-shaped overall structure, topical organization, lack of emphasis on description of methods, and heavy stress on recommendations, which separate them from research articles [8]. As business reports typically lack method descriptions, their validity is lower than that of most research articles. Using such reports as a data source therefore limits the research quality. However, the sole purpose of this research was to study available advice to a practical situation; how to approach Industry 4.0 strategically. In this respect, business reports are especially relevant, as they typically provide the readers, who are usually members of the business community, with necessary information to advice action in practical situations [8]. Finally, it is worth noting that such reports often adopt a positive tone to inspire confidence and optimism in problem-solving [8]. They are persuasive, 
as their authors are eager to sell their services to the readers. For this reason, there may be more emphasis on pros rather than cons in the reports. This should not pose a problem for this paper, as pros and cons of Industry 4.0, digitalization and automation are not within the scope of the research.

\section{$3 \quad$ Industry 4.0}

Industry 4.0 is a vision of the industrial production of the future [3]. '4.0' refers to a fourth industrial revolution expected to be realized by cyber-physical production systems that merge real and virtual worlds. It is a further developmental stage in the organization and management of the manufacturing industry, succeeding mechanical production powered by water and steam in the end of the $18^{\text {th }}$ century (first industrial revolution), mass production enabled by electrical energy in the start of the $20^{\text {th }}$ century (second industrial revolution) and further automated production through application of electronics and IT since the 1970s (third industrial revolution) [9]. While the concept of Industry 4.0 is widely used across Europe, commentators in the US and other parts of the English-speaking world also use terms like 'internet of things', the 'internet of everything' or the 'industrial internet' to describe the digital transformation which traditional manufacturing and production methods are in the middle of [9].

Industry 4.0 is triggered by digital technologies that have a disruptive impact on manufacturing companies' business models, the way they operate and create customer value [1]. Different terms are used to describe the trending technologies driving Industry 4.0. Boston Consulting Group [3] defines nine technology trends constitute the building blocks of Industry 4.0: The Industrial Internet of Things; big data and analytics; the cloud; simulation; augmented reality; autonomous robots; additive manufacturing; cybersecurity, and; horizontal and vertical system integration.

Industry 4.0 arises simultaneously with the coalesce of technologies into a digital ecosystem [1], and the terms 'digitalization' and 'Industry 4.0' are often used concomitantly - even though digitalization, which has already impacted all parts of society for years, has a much larger range than industrial production. For Industry 4.0, digitalization is specially related to connectivity and interaction among parts, machines and humans, which is expected to transform the design, manufacturing, operation and service of products and production systems [3]. Examples of new or improved ways of operating include predictive decision making through big data; reduced complexity through increased coordination; new forms of collaboration and coordination (e.g. sharing economy); flexibility in when and where to manufacture (e.g. micro customization) and digitally enhanced contribution to human productivity, from human judgement to machine intelligence $[1,10]$.

The new digital ecosystem is changing the way products are designed, created and delivered to customers [11]. While smart products, services and innovation are expected to leverage company growth, supply chains and factories are the main efficiency drivers of the new industrial paradigm [1]. Arguably, the transformation towards Industry 4.0 is a transformation of both factories and supply chains - from traditional factories to 'smart' [1], 'digital factories' [7] or 'factories of the future' [12], and from 
traditional supply chains to 'digital supply networks' $[11,13]$. These future-states are commonly characterized by a high degree of automation, integration and extensive information sharing. Efforts must be made both internally and externally to achieve this. For instance, products need to be developed in an integrated manner to ensure design for automated production, and core suppliers need to be involved when acquiring and developing tools for real-time information sharing and decision making throughout the supply chain.

\section{Strategic Landscape}

As noted in the Introduction, the transformation towards Industry 4.0 is a strategic imperative that requires a systematic approach. There exist different opinions of how the imminent technological opportunities should be addressed in a strategic manner.

Roughly speaking, two 'schools' have been identified when addressing strategies for digitalization and automation. The first advocates that the starting point for any digital journey is the definition of the company's digital vision and the resulting strategy [14]. This digital strategy sets the direction for a digital operating model, and in turn which digital technologies that should be used to digitalize core processes [5]. The second school argues that instead of developing digital strategies, companies should rethink their manufacturing and supply chain strategies in the light of digital technologies that enable e.g. increased flexibility and scalability $[7,15]$. In addition, some narrow the scope even further. For instance, to drive value and avoid incorrect insights from all the data that is currently gathered, some argue that companies should develop an enterprise data management strategy driven by business goals [16]. It is possible to envision that other digital technologies could have similar technology strategies. Finally, business goals are above the constantly shifting technology landscape [16]. Therefore, regardless of school of thought, it is generally agreed that any adoption of technology should in some way be linked to desired business outcomes $[5,7,10]$.

The Industry 4.0 strategy is located somewhere in between the two digitalization schools. Some simply state that companies need to define a tailored Industry 4.0 strategy to master the challenges of implementation [2]. Some go further in stating that the digital vision is the starting point to Industry 4.0 [1], which would imply that the digital vision sets the direction for the Industry 4.0 strategy. However, a clear relationship between the Industry 4.0 strategy and other strategies has not been identified. In the previous section it was argued that the transformation towards Industry 4.0 is a transformation of both factories and supply chains. With the same reasoning, it is proposed that an Industry 4.0 strategy is in fact the sum of a manufacturing and supply chain strategy enabled by digital technologies.

From this, a 'strategic landscape' of Industry 4.0 is proposed (Fig. 1). The dashed vertical line is used to separate the two schools of thought proposed above. The lefthand side of the line has a strong emphasis on digitalization (often, for the sake of digitalization), while the right-hand side sees digitalization as something that enables manufacturing and supply chain strategies to contribute more to business strategy, models and goals. The equal- and plus signs are used to show how the sum of the digitally 
enabled manufacturing and supply chain strategy amounts to an Industry 4.0 strategy. At the rightmost side of the landscape are specific technology strategies, which are driven by business strategy, and may instruct how to treat specific technologies. An example is the data management strategy mentioned above.

Fig. 1. The Strategic Landscape of Industry 4.0

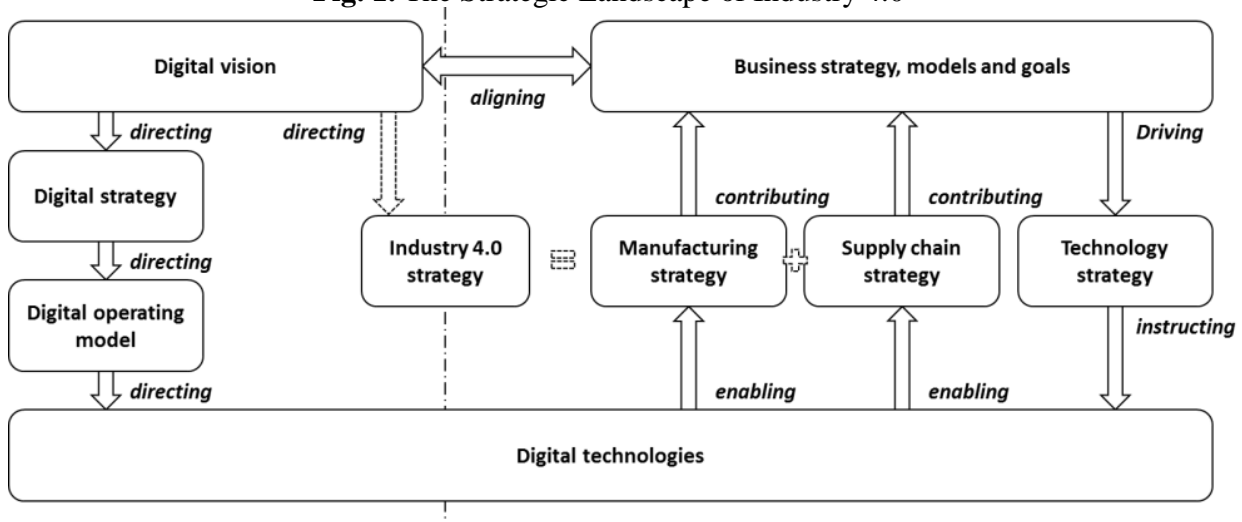

\section{$5 \quad$ Discussion and Conclusion}

The strategic landscape (Fig. 1) illustrates what many companies are facing at the outset of their digital journey; a myriad of partly conflicting opinions about how to approach Industry 4.0 and related topics. As such, it can be argued that its contribution lies in refining the problem, rather than bringing the answers to it. Still, there are some takeaways. First, a company should question whether it needs a dedicated Industry 4.0 strategy if it already has a manufacturing and/or supply chain strategy. The question of how digital technologies may serve as enablers is something that can be treated directly in these strategies, instead of in an additional Industry 4.0 strategy. On the other hand, if a company lacks a manufacturing and/or supply chain strategy, an Industry 4.0 strategy may serve this purpose. Further, a company could benefit from having a digital vision even if it does not develop a digital strategy, a digital operating model, and so on. For example, such a vision could dictate the company's policy about adopting new technology early versus only using mature technology. Alignment with business strategy, models and goals is always key. Finally, there is a question of what school is the best to follow. While the left-hand side of the strategic landscape may be more fit for the Netflixes and Spotifys of the world, some production companies may still find value in developing digital strategies and operating models. As seen in the framework, it is important to ensure that the technological directions that come out of these strategies and models are not in conflict with the technological trajectories best fit for manufacturing and supply chain management.

When companies have found their position in their strategic landscape, they must add content to their strategies. While this is largely company-specific, some topics are likely to be relevant for multiple companies. Further research includes identifying these 
topics and developing guidelines for strategy development within the strategic landscape. This could provide companies with a more systematic approach towards Industry 4.0. After all, "digital is too critical to a company's competitiveness to be left to chance" [7].

Acknowledgements. This work has been conducted within the project SmartChain funded by the Research Council of Norway. The author would like to thank the participants of the project for valuable discussions and feedback while developing the framework.

\section{References}

1. Bechtold, J., Kern, A., Lauenstein, C., Bernhofer, L.: Industry 4.0 - The Capgemini Consulting View. Sharpening the Picture beyond the Hype. Capgemini Consulting (2014)

2. Lorenz, M., Küpper, D., Rüßmann, M., Heidemann, A., Bause, A.: Time to Accelerate in the Race toward Industry 4.0. Boston Consulting Group (2016)

3. Rüßmann, M., Lorenz, M., Gerbert, P., Waldner, M., Justus, J., Engel, P., Harnisch, M.: Industry 4.0: The Future of Productivity and Growth in Manufacturing Industries. Boston Consulting Group (2015)

4. Hajibashi, M., Bhatti, A.: Supply Chain for a New Age. Accenture (2017)

5. Raab, M., Griffin-Cryan, B.: Digital Transformation of Supply Chains: Creating Value - When Digital Meets Physical. Capgemini Consulting (2011)

6. Ebner, G., Bechtold, J.: Are Manufacturing Companies Ready to Go Digital? Understanding the Impact of Digital. Capgemini Consulting (2012)

7. Rasmus, R., Nichols, J.: Digital Factory: Cracking the Code to Success. Accenture (2017)

8. Yeung, L.: In search of commonalities: Some linguistic and rhetorical features of business reports as a genre. English for specific purposes 26, 156-179 (2007)

9. Schlaepfer, R.C., Koch, M.: Industry 4.0: Challenges and Solutions for the Digital Transformation and Use of Exponential Technologies. Deloitte (2015)

10. Schmidt, B., Rutkowsky, S., Petersen, I., Klötzke, F., Wallenburg, C.M., Einmahl, L.: Digital Supply Chains: Increasingly Critical for Competitive Edge. AT Kearney (2015)

11. Mussomeli, A., Gish, D., Laaper, S.: The Rise of the Digital Supply Network: Industry 4.0 Enables the Digital Transformation of Supply Chains. Deloitte (2016)

12. Küpper, D., Kuhlmann, K., Köcher, S., Dauner, T., Burggräf, P.: The Factory of the Future. Boston Consulting Group (2016)

13. Hanifan, G., Sharma, A., Newberry, C.: The Digital Supply Network: A New Paradigm for Supply Chain Management. Accenture (2014)

14. Hégelé, M., Tarnopolski, J., Aggarwal, P.: Digital Supply Chain Planning in Chemicals: Mastering six capabilities to win. Accenture (2016)

15. Hanifan, G.L.: Is Your Supply Chain a Growth Engine? It Could Be If You Leverage Digital Technologies. Accenture (2015)

16. Alexander, M., Brody, P., Chadam, J., Cookson, C., Little, J., Meadows, B.: Digital Supply Chain: It's all about that Data. EY (2016) 